Article

\title{
Uncertainty Representation Method for Open Pit Optimization Results Due to Variation in Mineral Prices
}

\author{
Jieun Baek ${ }^{1}$, Yosoon Choi ${ }^{1, *}$ and Han-su Park ${ }^{2}$ \\ 1 Department of Energy Resources Engineering, Pukyong National University, Busan 608-737, Korea; \\ bje0511@gmail.com \\ 2 Daesung Mining Development Inc., Seoul 110-885, Korea; parkhs@dsmd.co.kr \\ * Correspondence: yspower7@gmail.com or energy@pknu.ac.kr; Tel.: +82-51-629-6562; Fax: +82-51-629-6553
}

Academic Editor: Michael Hitch

Received: 27 December 2015; Accepted: 18 February 2016; Published: 24 February 2016

\begin{abstract}
This study proposes a new method to quantitatively represent the uncertainty existing in open pit optimization results due to variations in mineral prices. After generating multiple mineral prices using Monte Carlo simulation with data on past mineral prices, a probability model that represents the uncertainty was developed by integrating multiple open pit optimization results derived from the mineral prices. The results of applying the proposed method to the copper-zinc deposits showed that significant uncertainty exists in open pit optimization results due to the variation in copper prices. It was also found that the method has a potential as a tool for classifying the estimation results of ore reserve based on confidence level.
\end{abstract}

Keywords: uncertainty; open pit optimization; Monte Carlo simulation; revenue factor; ore reserve estimation

\section{Introduction}

Determination of optimal open pit boundary is extremely important in planning an open pit mine. This is because profitability may vary significantly depending on the determination of open pit boundary. Algorithms to solve the open pit optimization problem have been developed by many researchers. Lerchs and Grossmann [1] developed an open pit optimization algorithm based on graph theory. In 1968, Johnson proposed the method to determine optimized pit boundary using network flow algorithm, which was verified by Picard [2]. David et al. [3] developed the Korobov algorithm, and Lane [4] introduced the concept of cut-off grade to the open pit optimization problem. Caccetta and Giannini [5] presented a dynamic programming method to implement the Lerchs and Grossmann algorithm. Berlanga et al. [6] developed the floating cone algorithm that can optimize open pit boundaries based on heuristic theory. Zhao and Kim [7] modified the Lerchs and Grossmann algorithm to take into account the boundary of ore and waste. Dowd and Onur [8] modified the Korobov algorithm to overcome its limitations, and Yamatomi et al. [9] presented an improvement plan for the floating cone algorithm. Underwood and Tolwinsk [10] developed an improved network flow algorithm, and Hochbaum and Chen [11] suggested the push-label algorithm by modifying the Lerchs and Grossmann algorithm. In addition, there have been many studies to solve the production scheduling optimization problems in open pit mines [12-29]. 
Open pit optimization algorithms determine the scope of deposit development required to ensure profitability while meeting the requirements for mine development. In the determination, the Block Economic Value (BEV) calculated in a block unit is usually used as input data for the algorithm. $\mathrm{BEV}$ represents the revenue estimated by dividing the 3D ore body model created based on geological data into blocks, and then considering sales revenue and production cost for each block. The problem is that $\mathrm{BEV}$ determined as a single value contains significant uncertainty due to the variations in mineral prices, production costs, and exchange rates. Consequently, the products of the open pit optimization algorithms that use BEV as input data also inevitably contain uncertainty.

A number of methods to consider this uncertainty have been developed to date. Godoy [30] developed a method to quantify the geological uncertainty in long-term production scheduling of open pit mines, and Menebde et al. [31] treated the uncertainty in BEV using conditional simulation methods. Gabriel et al. [32] developed a model to evaluate rates of return of mining projects by considering uncertainties such as mineral prices, production costs, and tax. Golamnejad et al. [33] considered the uncertainty in BEV using probability models. Dimitrakopoulos and Sabour [34] proposed the Real Option Valuation (ROV) technique to evaluate mining projects by considering uncertainty of economic variables. Ramazan and Dimitrakopoulos [35] provided a new integer programming formulation for stochastic optimization of long-term production scheduling by considering the uncertainty of geological variables. Boland et al. [36] suggested a multistage stochastic programming approach to open pit mine production scheduling with uncertain geology. Akbari et al. [37] performed open pit optimization considering uncertainty of mineral prices, and Albor and Dimitrakopoulos [38] developed a method to simultaneously consider the uncertainties of multiple variables in push back design of open pit mines.

Sabour and Dimitrakopoulos [39] developed the technique to generate multiple open pit optimization results considering uncertainty of economic and geological variables, and then prioritizing the results. Evatt et al. [40] provided a method to estimate ore reserves under mineral price uncertainty, Lamghari and Dimitrakopoulos [41] considered the uncertainty of metal contents in mine production scheduling problems by a diversified Tabu search approach. Asad and Dimitrakopoulos [42] developed a parametric maximum flow algorithm for optimal open pit mine design under uncertain market conditions. Furthermore, Alonso-Ayuso et al. [43] provided a method to optimize the copper extraction planning considering the uncertainty in future copper prices, and Kizilkale and Dimitrakopoulos [44] presented a distributed and dynamic programming framework to the mining production rate target tracking of multiple metal mines under financial uncertainty. However, no study has been conducted to quantitatively represent the uncertainty itself inevitably present in open pit optimization results using probability models or other methods.

Thus, the objective of this study is to present a method to quantitatively represent the uncertainty included in open pit optimization results due to variation in mineral prices. In this study, multiple mineral prices are generated using Monte Carlo simulation based on past mineral prices data, and open pit optimization is conducted iteratively using the generated prices. The study aims to generate a probability model to quantitatively represent the uncertainty due to variation in mineral prices by integrating multiple open pit optimization results generated by iterative calculation. This paper describes the method to represent the uncertainty in open pit optimization results due to variation in mineral prices, and presents the results of applying the method to copper-zinc deposits.

\section{Methods}

The method developed in this study to represent uncertainty in open pit optimization results due to variation in mineral prices consists of four steps (see Figure 1). 


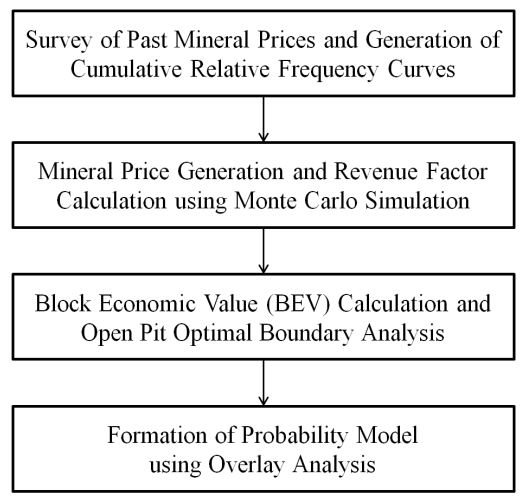

Figure 1. Study process of uncertainty representation for pit optimization results using the proposed method.

\subsection{Survey of Past Mineral Prices and Generation of Cumulative Relative Frequency Curves}

To investigate the variations in mineral prices, data on mineral price of the past over a long period are collected, and statistics such as maximum values, minimum values, and the means of the collected data are obtained using statistical analysis. Using the results of statistical analysis, the class width required for creating cumulative relative frequency curves of mineral prices can be calculated (see Equation (1)). In general, the number of classes is set as between 10 and 20,

$$
\text { Class width }=\frac{\text { Maximum value }- \text { Minimum value }}{\text { Number of classes }}
$$

Once the class width is determined, the frequency of data included in each class is obtained by examining the collected data on mineral prices, and the relative frequency of each class is calculated by dividing the data frequency of each class by the total number of data (see Equation (2)). Cumulative relative frequency can be calculated using the relative frequency of each class (see Equation (3)).

$$
\begin{gathered}
\mathrm{F}_{i}^{r}=\frac{f_{i}}{N} \\
\mathrm{~F}_{n}^{c}=\sum_{i=1}^{n} \mathrm{~F}_{i}^{r}
\end{gathered}
$$

Here, $\mathrm{F}_{i}^{r}$ denotes the relative frequency of $i$-th class, $f_{i}$ denotes the data frequency of $i$-th class, $N$ denotes the total number of data, and $\mathrm{F}_{n}^{c}$ denotes the cumulative relative frequency of $n$-th class.

In addition, the cumulative relative frequency curve can be generated by plotting the mineral prices on the $x$-axis and cumulative relative frequencies on the $y$-axis.

\subsection{Mineral Price Generation and Revenue Factor Calculation Using Monte Carlo Simulation}

When using a cumulative relative frequency curve of past mineral prices generated in the previous step, $n$ mineral prices can be generated based on Monte Carlo simulation as follows:

$$
\mathrm{F}(x)=\mathrm{P}(X \leqslant x)
$$

The function of cumulative relative frequency curve $\mathrm{F}(x)$ gives the probability $\mathrm{P}$ that the mineral price $X$ will be less than or equal to $x$. Because $\mathrm{F}(x)$ obviously ranges from zero to one, we can look at this equation in the reverse direction to find the value of $x$ for a given value of $\mathrm{F}(x)$ as follows:

$$
\mathrm{G}(\mathrm{F}(x))=\mathrm{G}(r)=x
$$


Here, $\mathrm{G}(\mathrm{F}(x))$ is the inverse function, $r$ is a random real number between zero and one.

In this study, $n$ mineral prices are generated by generating $n$ random real numbers between zero and one, and then assuming each generated real number as the $y$ value of the cumulative relative frequency curve, and finding $x$ values corresponding to the $y$ values.

Next, using the generated $n$ mineral prices, $n$ revenue factors (RF) are calculated (see Equation (6)). The revenue factor represents the ratio of the uncertain future mineral price (SP) to the current mineral price $(\mathrm{CP})$. Because RF can indicate the increase or decrease of mineral price, the change in optimal open pit boundary as a result of mineral price can be analyzed using RF [45],

$$
\mathrm{RF}=\frac{\mathrm{SP}}{\mathrm{CP}}
$$

\subsection{Block Economic Value (BEV) Calculation and Open Pit Optimal Boundary Analysis}

In the proposed model, $n$ BEVs are calculated for all blocks using the RF values calculated in the previous step (see Equations (7)-(9)):

$$
\begin{gathered}
\mathrm{BEV}(\text { ore })=T_{o} \times(g \times r \times(\mathrm{RF} \times \mathrm{P}-\mathrm{SC})-\mathrm{PC}-\mathrm{MC}) \\
\mathrm{BEV}(\text { waste })=T_{w} \times \mathrm{MC} \\
\mathrm{BEV}=\mathrm{BEV}(\text { ore })-\mathrm{BEV}(\text { waste })
\end{gathered}
$$

Here, $T_{o}$ denotes the mass of ore block (tonne), $g$ denotes the grade of ore, $r$ denotes recovery of ore, RF denotes revenue factor, $\mathrm{P}$ denotes the price of mineral ( $\$ /$ tonne), SC denotes selling cost (\$/tonne), PC denotes processing cost (\$/tonne), MC denotes mining cost (\$/tonne), and $T_{w}$ denotes the mass of waste block (tonne).

Once $n$ BEV values for all blocks have been calculated, open pit optimal boundary can be determined by inputting the values in optimization algorithms such as the Lerchs-Grossmann algorithm, Korobov algorithm and floating cone algorithm. This study used the floating cone algorithm proposed by Berlanga et al. [6]. For each block with a positive BEV value, the floating cone algorithm involves constructing a cone with sides oriented parallel to the pit slope angles, and then determining the value of the cone by summing the values of blocks enclosed within it. If the value of the cone is positive, all blocks within the cone are mined. This process starts from the uppermost level and moves downward searching for positive blocks. The process continues until no positive cones remain in the block model [46]. An advantage of the floating cone algorithm is its speed of calculation [47]. Therefore, it is useful when optimal boundary analysis needs to be performed many times, as in this study. Other open pit optimization algorithms can be used in this step, however the comparison of results from different optimization algorithms is beyond the scope of this study. Interested readers should refer to texts such as Hustralid et al. [48].

As $n$ BEVs are calculated, the pit boundary optimization process is also conducted $n$ times, and as a result, $n$ optimization results are generated.

\subsection{Formation of Probability Model Using Overlay Analysis}

In the final step, a probability model is developed by overlaying $\mathrm{n}$ open pit optimization results into one (Figure 2). To that end, the results of open pit optimal boundary analysis are examined; 1.0 is assigned if a block exists within the optimal boundary, and 0.0 is assigned otherwise. This binarization is performed on $n$ results of optimal boundary analysis. After completing binarization, a probability model is formed by averaging the values assigned to all blocks (see Equation (10)).

$$
\mathrm{Z}=\frac{1}{n} \times \sum_{i=1}^{n} z_{i}
$$



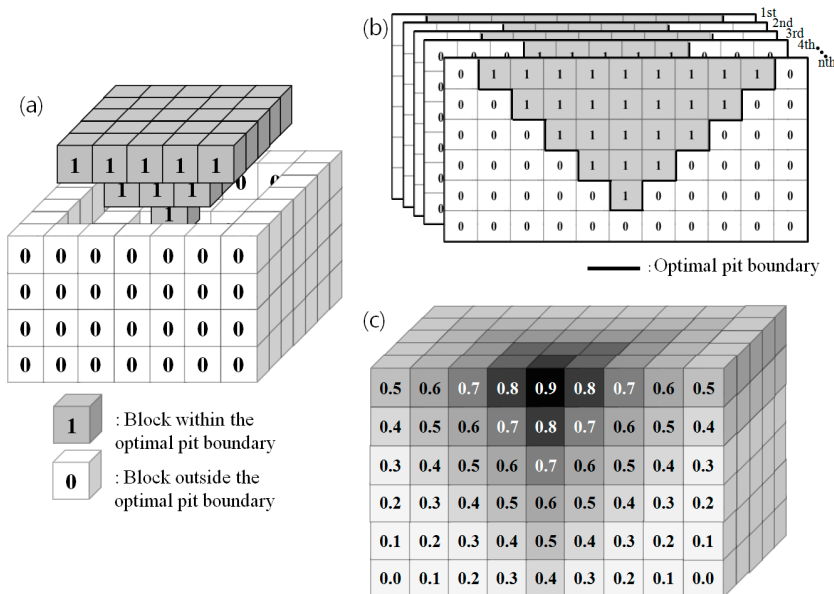

Figure 2. Example of probability model formation representing the uncertainty. (a) Binarized block model; (b) Probability model formation by overlay analysis; (c) Sectional view of probability model.

Here, $Z$ denotes the probability that a block exists within the open pit optimal boundary (0.0-1.0), and $z_{i}$ denotes the binarized value assigned to the result of $i$-th open pit optimal boundary analysis. $Z$ should be calculated for all blocks.

\section{Study Area and Data}

The uncertainty representation method of open pit optimization results due to variation in mineral prices developed in this study was applied to copper-zinc deposits located in the OO region. The ore body was widely distributed in a plate form (Figure 3). This region has the sea-level altitude of about $150 \mathrm{~m}$, relatively flat terrain, and adequate infrastructure for mine development as there is a mining city in the vicinity.

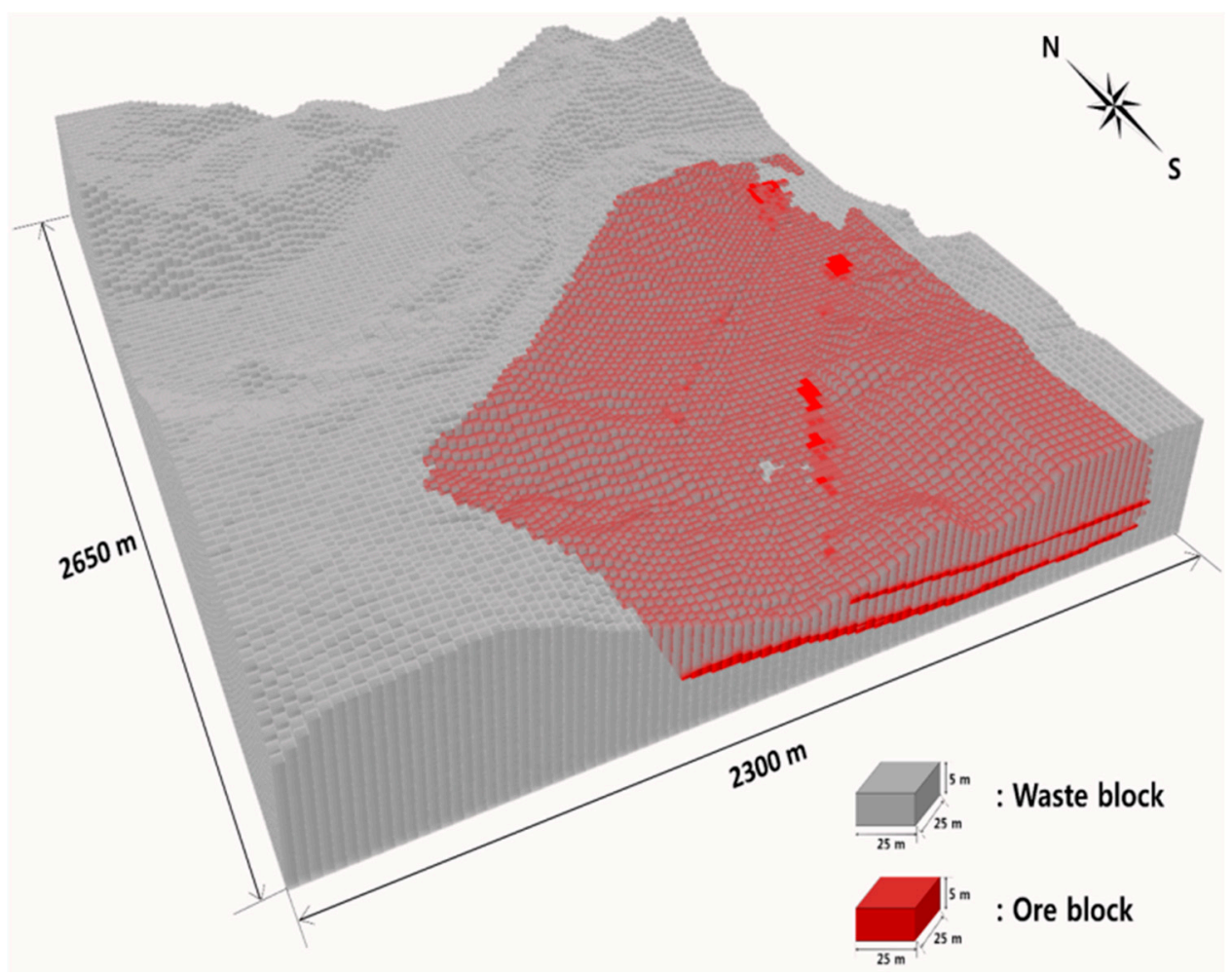

Figure 3. Block model of copper-zinc deposits in the study area. 
The block model of ore body used in this study is $25 \mathrm{~m} \times 25 \mathrm{~m} \times 5 \mathrm{~m}$ blocks. The number of blocks is 92 on the axis $x$ (easting), 106 on the axis $y$ (northing), and 74 on the axis $z$ (elevation). Each block is classified into ore or waste and includes information on mass. In addition, ore blocks have grades of copper and zinc assigned to them. The mean grade is about $0.84 \%$ for copper, and about $0.21 \%$ for zinc.

\section{Results}

\subsection{Results of Cumulative Relative Frequency Curves of Copper and Zinc}

To examine the variation in metal prices, the data on copper and zinc prices for about 10 years (January 2005-April 2015) published by the London Metal Exchange (LME) were collected and analyzed (Figure 4). The results showed that the mean copper price for the past 10 years is $6796 \$$ /tonne, the maximum price was $10,148 \$ /$ tonne, and the minimum price was $2770 \$ /$ tonne. In the case of zinc, the mean price for the past 10 years was $2109 \$ /$ tonne, the maximum price was $4620 \$ /$ tonne, and the minimum price was $1042 \$ /$ tonne.

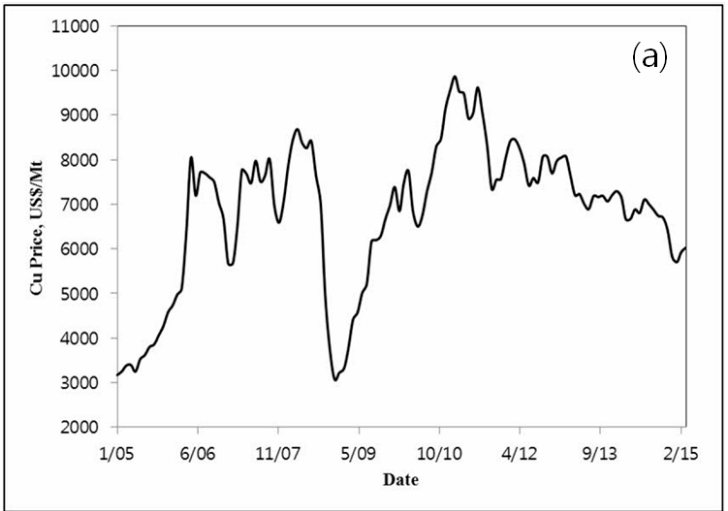

(a)

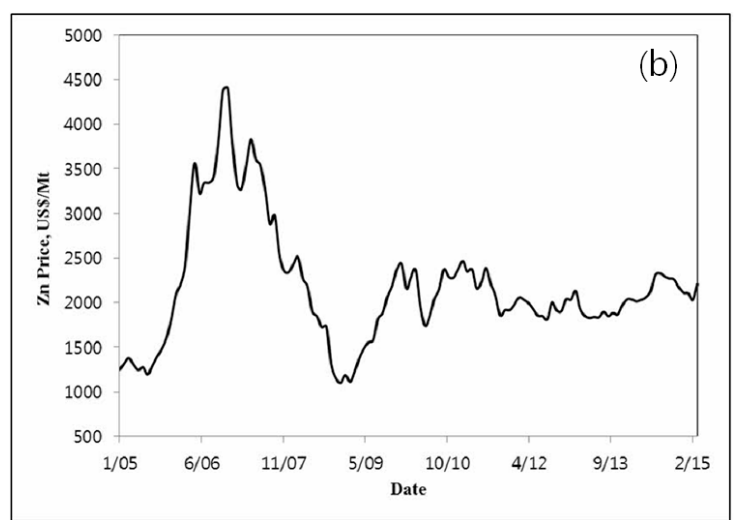

(b)

Figure 4. Price fluctuation graph. (a) Average monthly copper prices; (b) Average monthly zinc prices.

To plot a cumulative relative frequency curve, the number of classes for copper prices was set at 13 , and class width was set at $600 \$ /$ tonne based on Equation (1). In the same manner, the number of classes for zinc prices was set at 12 , and class width was set at $300 \$ /$ tonne. The results of calculating frequency of each class, relative frequency, and cumulative relative frequency using the copper and zinc prices for the past 10 years are shown in Table 1 (copper) and Table 2 (zinc). Figure 5 shows the cumulative relative frequency curves of copper and zinc prices for the past 10 years.

Table 1. Cumulative relative frequency of copper prices.

\begin{tabular}{cccc}
\hline Class Interval (\$/tonne) & Frequency & Relative Frequency & Cumulative Relative Frequency \\
\hline $2700-3300$ & 92 & 0.0353 & 0.0353 \\
$3300-3900$ & 181 & 0.0694 & 0.1047 \\
$3900-4500$ & 91 & 0.0349 & 0.1396 \\
$4500-5100$ & 125 & 0.0479 & 0.1876 \\
$5100-5700$ & 84 & 0.0322 & 0.2198 \\
$5700-6300$ & 144 & 0.0552 & 0.2750 \\
$6300-6900$ & 340 & 0.1304 & 0.4054 \\
$6900-7500$ & 590 & 0.2263 & 0.6318 \\
$7500-8100$ & 442 & 0.1695 & 0.8013 \\
$8100-8700$ & 290 & 0.1112 & 0.9125 \\
$8700-9300$ & 121 & 0.0464 & 0.9590 \\
$9300-9900$ & 95 & 0.0364 & 0.9954 \\
$9900-10,500$ & 12 & 0.0046 & 1.0000 \\
\hline
\end{tabular}


Table 2. Cumulative relative frequency of zinc prices.

\begin{tabular}{cccc}
\hline Class Interval (\$/tonne) & Frequency & Relative Frequency & Cumulative Relative Frequency \\
\hline $1000-1300$ & 224 & 0.0859 & 0.0859 \\
$1300-1600$ & 193 & 0.0740 & 0.1600 \\
$1600-1900$ & 470 & 0.1803 & 0.3402 \\
$1900-2200$ & 729 & 0.2796 & 0.6199 \\
$2200-2500$ & 532 & 0.2041 & 0.8239 \\
$2500-2800$ & 66 & 0.0253 & 0.8493 \\
$2800-3100$ & 61 & 0.0234 & 0.8727 \\
$3100-3400$ & 116 & 0.0445 & 0.9171 \\
$3400-3700$ & 118 & 0.0453 & 0.9624 \\
$3700-4000$ & 42 & 0.0161 & 0.9785 \\
$4000-4300$ & 23 & 0.0088 & 0.9873 \\
$4300-4600$ & 31 & 0.0119 & 0.9992 \\
$4600-4900$ & 2 & 0.0008 & 1.0000 \\
\hline
\end{tabular}

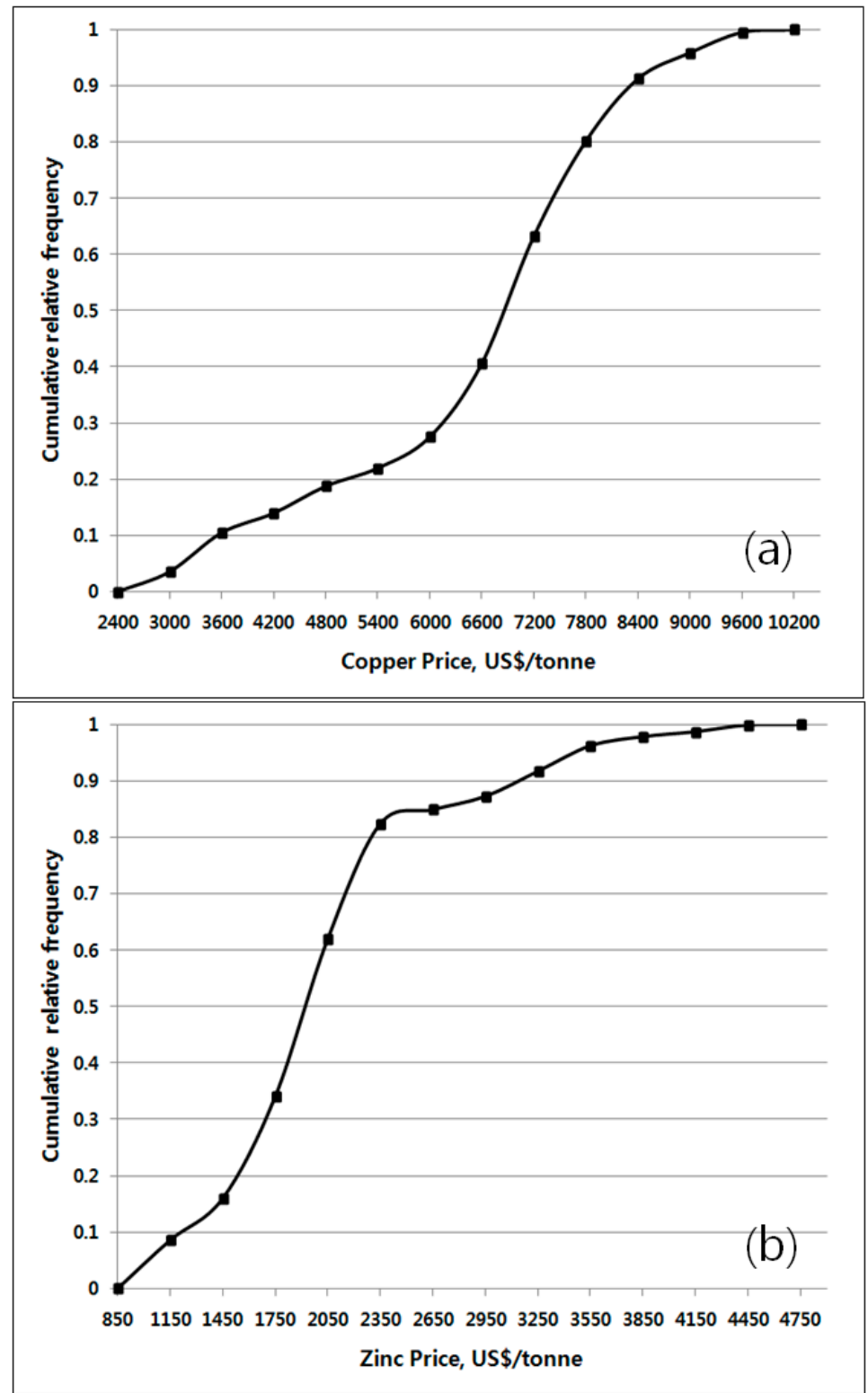

Figure 5. Cumulative relative frequency curves. (a) Copper prices; (b) Zinc prices. 


\subsection{Revenue Factor of Copper and Zinc Price Calculation Results Using Monte Carlo Simulation}

Using the cumulative relative frequency curves of copper and zinc prices shown in Figure 5, 100 copper prices and 100 zinc prices were generated using Monte Carlo simulation (Figure 6). In the 100 copper prices generated by Monte Carlo simulation, the mean was $6591.13 \$ /$ tonne, the maximum was 9486.18 \$/tonne, and the minimum was $3342.66 \$ /$ tonne. In addition, in the 100 zinc prices generated, the mean was $1985.00 \$ /$ tonne, the maximum was $3571.96 \$ /$ tonne, and the minimum was $924.44 \$ /$ tonne.
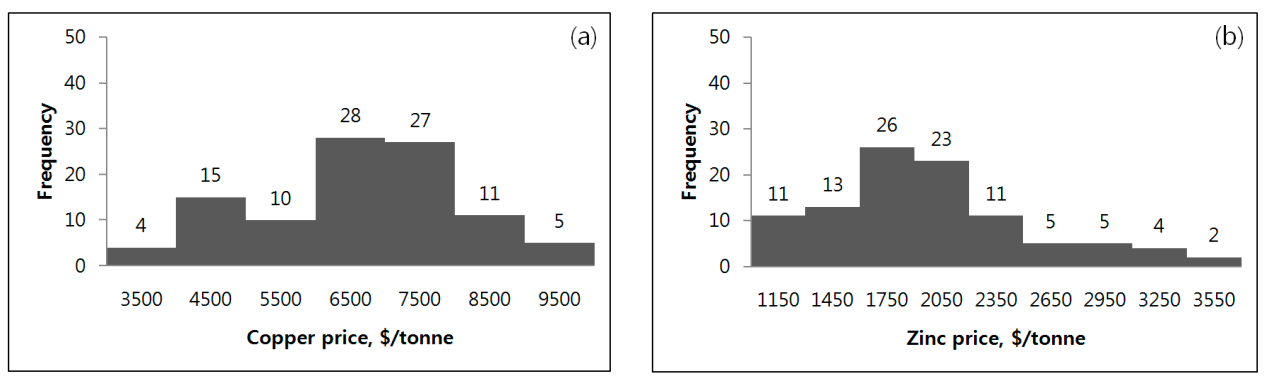

Figure 6. Results from Monte Carlo simulations. (a) Histogram of randomly extracted copper prices; (b) Histogram of randomly extracted zinc prices.

By entering the generated copper prices and zinc prices in Equation (6), RF was estimated. For the reference price for the minerals, the monthly average copper price of $6027.96 \$ /$ tonne and monthly average zinc price of $2206.90 \$$ /tonne, published by LME for April 2015 when this study was conducted, were used. As the numbers of previously generated copper prices and zinc prices were 100 each, $100 \mathrm{RF}$ values were also estimated for each. Figure 7 shows the estimated RFs of copper and zinc represented in the histogram.
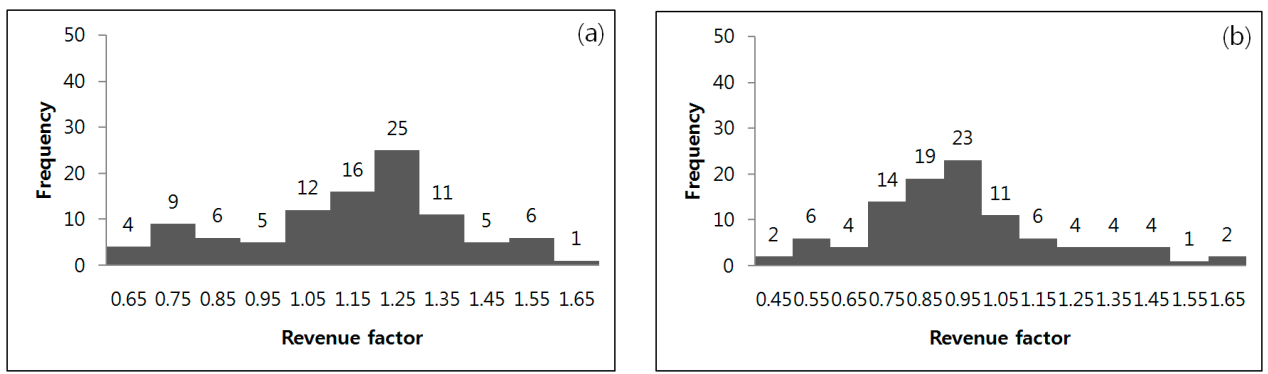

Figure 7. Results from revenue factor calculation. (a) Histogram of revenue factors related to copper prices; (b) Histogram of revenue factors related to zinc prices.

\subsection{BEV Calculation and Open Pit Optimal Boundary Analysis Results}

The BEV for the block model of the study area shown in Figure 3 was calculated using Equation (11), instead of Equation (7), because the study area has copper-zinc mixed deposits,

$$
\mathrm{BEV}(\text { ore })=T_{o} \times\left[g_{c u} \cdot r_{c u} \cdot\left(\lambda_{c u} \cdot P_{c u}-\mathrm{SC}\right)+g_{z n} \cdot r_{z n} \cdot\left(\lambda_{z n} \cdot P_{z n}-\mathrm{SC}\right)-\mathrm{PC}-\mathrm{MC}\right]
$$

Here, $T_{o}$ denotes the mass of ore block (tonne), $g_{c u}$ denotes the grade of copper ore (grade), $g_{z n}$ denotes the grade of zinc (grade), $r_{c u}$ denotes recovery of copper ore (recovery), $r_{z n}$ denotes recovery of copper ore (recovery), $\lambda_{c u}$ denotes RF of copper, $\lambda_{z n}$ denotes RF of zinc (RF), $P_{c u}$ denotes the price of copper mineral (\$/tonne), $P_{z n}$ denotes the price of zinc mineral (\$/tonne), SC denotes selling costs of ore (\$/tonne), PC denotes of processing costs of ore (\$/tonne), and MC denotes mining costs of ore (\$/tonne). The factor values assumed in this study to calculate BEV are presented in 
Table 3. As 100 copper RFs and 100 zinc RFs were estimated, the BEV calculation of the block model of the study area was also conducted 100 times.

Table 3. Economic parameters for calculating blocks' economic values.

\begin{tabular}{cccc}
\hline Input Parameters & Unit & Copper & Zinc \\
\hline Price of metal $(P)$ & $\$ /$ tonne & 6027.96 & 2206.90 \\
Recovery $(r)$ & $\%$ & 0.90 & 0.65 \\
Selling cost $(\mathrm{SC})$ & $\$ /$ tonne & 120.00 & 120.00 \\
Mining cost $(\mathrm{MC})$ & $\$ /$ tonne & 2.70 & 2.70 \\
Processing cost $(\mathrm{PC})$ & $\$ /$ tonne & 40.08 & 40.08 \\
\hline
\end{tabular}

The previously calculated block model's BEVs were entered into the floating cone algorithm for analyzing optimal pit boundaries, and it was assumed that the angle of the slope was $45^{\circ}$ and that cutoff grade was $0.007 \%$, incorporating copper prices. As $100 \mathrm{BEVs}$ of block model were estimated for each, the boundary optimization with the floating cone algorithm was also conducted 100 times.

Figure 8 shows graphical representation of five open pit optimization results arbitrarily selected from 100 results. They demonstrate that when the RF of copper applied in BEV calculation increases, the open pit boundary increases gradually.

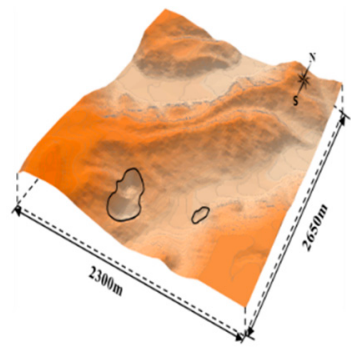

(a)

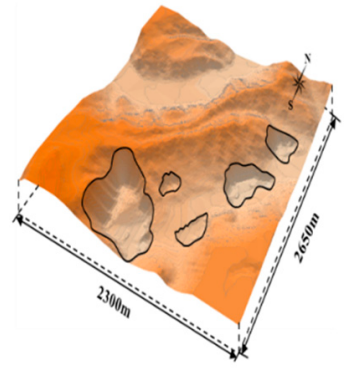

(d)

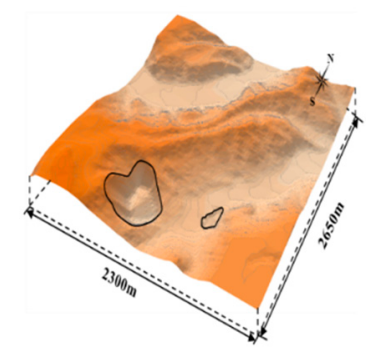

(b)

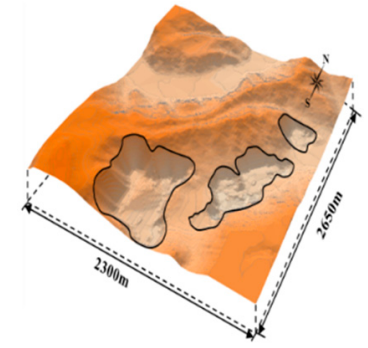

(e)

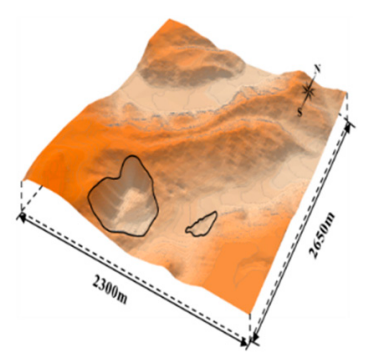

(c)

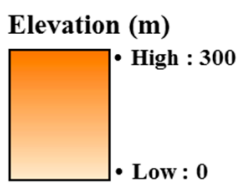

Figure 8. Pit optimization results using the floating cone algorithm. (a) Result No. 34 (Revenue Factor (RF) of $\mathrm{Cu}=0.86$, RF of $\mathrm{Zn}=0.79$ ); (b) Result No. 25 (RF of $\mathrm{Cu}=1.01$, RF of $\mathrm{Zn}=1.00$ ); (c) Result No. 55 $(\mathrm{RF}$ of $\mathrm{Cu}=1.17$, RF of $\mathrm{Zn}=0.91$ ); (d) Result No. 11 (RF of $\mathrm{Cu}=1.34$, RF of $\mathrm{Zn}=1.58$ ); (e) Result No. 21 $(\mathrm{RF}$ of $\mathrm{Cu}=1.57, \mathrm{RF}$ of $\mathrm{Zn}=1.14)$.

\subsection{Results of Probability Model Formation}

A probability model was formed by overlaying 100 open pit optimization results of the study area into one according to the method described in Section 2.4. Figure 9 shows the plan view of the probability model. The optimal open pit boundaries estimated when the RFs of copper and zinc were 1.0 (i.e., when the mineral prices of April 2015) are shown by the black solid lines. Each block has a value between 0.0 and 1.0, and the value indicates the probability that the block is included in the optimal boundary of open pit. 


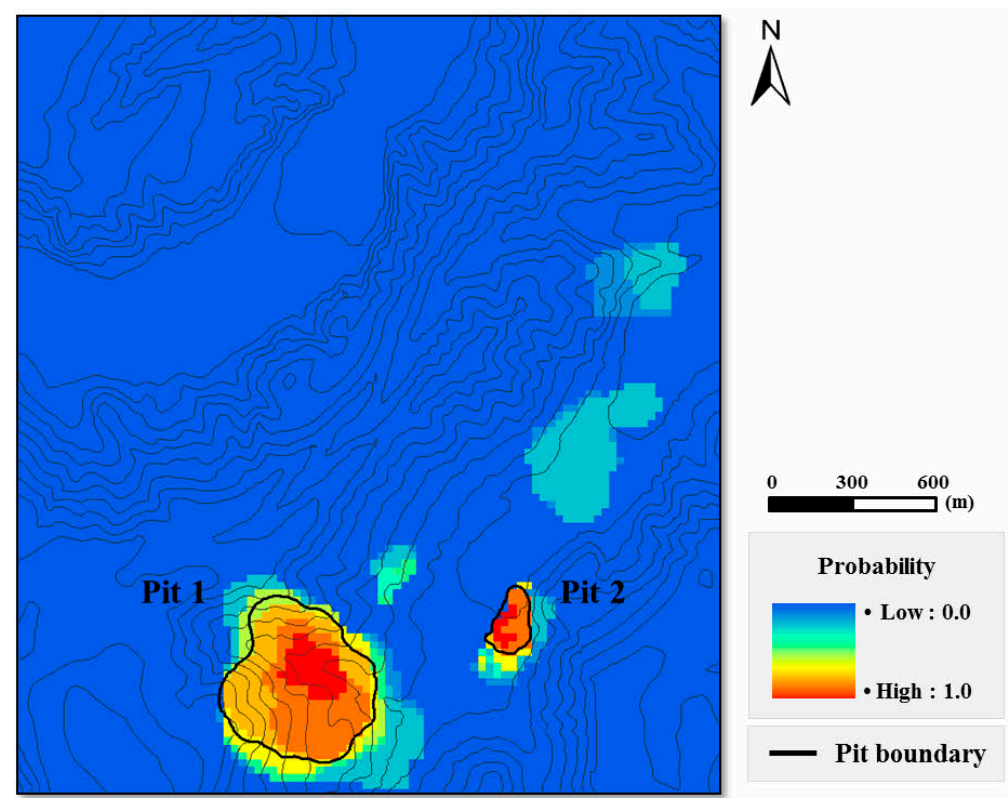

Figure 9. Probability model representing the uncertainty in the pit optimization results.

When the uncertainty of the open pit optimization results due to the variation in mineral prices is large, many blocks with probabilities greater than 0.0 exist outside the open pit optimal boundary for the RF of 1.0, or many blocks with probabilities smaller than 1.0 exist inside the optimal boundary. On the other hand, when the uncertainty of open pit optimization results due to the variation in mineral prices is small, there are many blocks with probability of 1.0 inside the open pit optimal boundary for the RF of 1.0, and many blocks with probability of 0.0 outside the boundary.

The probability model showed that significant uncertainty exists in open pit optimization results considering the variation in copper and zinc prices in the past 10 years. It was found that when copper and zinc prices decrease from current reference prices, the probability that the open pit boundary for RF of 1.0, which is shown by the solid black line (Figure 9), satisfies the optimal boundary is about $70 \%$ or higher for Pit 1 and about $80 \%$ or higher for Pit 2 . It is believed that when resetting the optimal open pit boundary based on only the blocks with probability higher than the aforementioned probabilities (e.g., 90\% or higher), the size of the open pit will be smaller than that for RF of 1.0.

On the other hand, if copper and zinc prices increase from the current reference prices, it is possible that the optimal open pit boundary further expands from the solid black line, and Figure 9 shows the probabilities that the blocks are located within the open pit boundary. East of the study area, there is a possibility that an additional open pit can be formed if mineral prices increase; however, the probability is not high, at $20 \%$.

\subsection{Deposit Reserve Estimation as a Function of Confidence Level}

Figure 10 is a visual representation of the blocks that will be distributed within the open pit optimal boundary despite the variation in copper and zinc prices, using the probability model formation results. The results of graphic representation of the blocks to be distributed within the optimal boundary by applying three confidence levels (90\% or higher, $80 \%$ or higher, and $70 \%$ or higher) showed that setting confidence level higher resulted in a smaller size of open pit, and setting confidence level lower resulted in a larger size of open pit. 


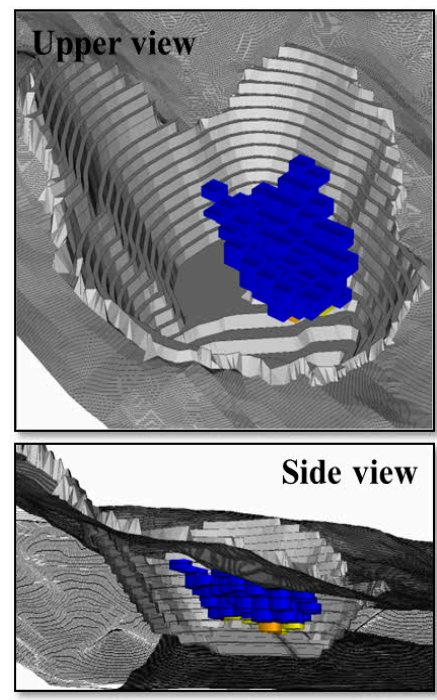

(a)

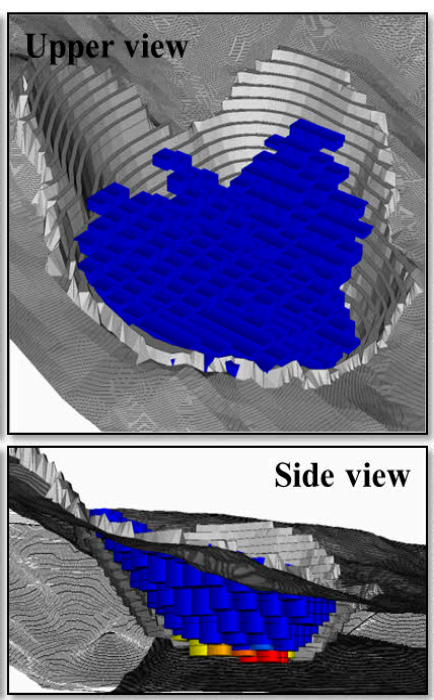

(b)

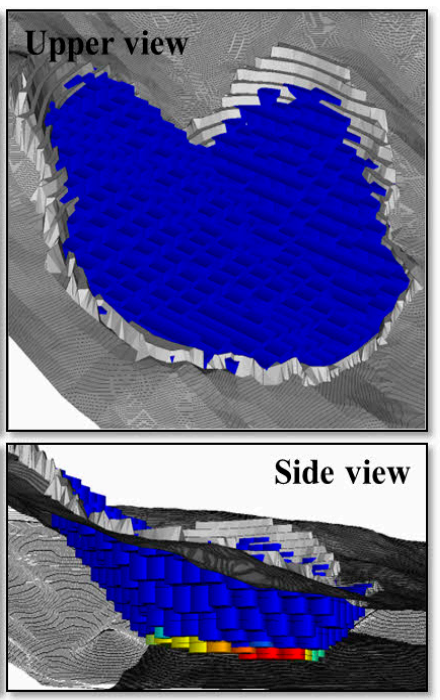

(c)

Figure 10. Blocks representing ore reserve above optimal pit boundary. (a) Case 1: probability $\geqslant 90 \%$; (b) Case 1: probability $\geqslant 80 \%$; (c) Case 1: probability $\geqslant 70 \%$.

After extracting the blocks to be distributed within the optimal boundary of the study area by applying various confidence levels, the ore reserve was estimated based on the extracted blocks, and the results are shown in Figure 11. It was found that when confidence level was set at $90 \%$ or higher, ore reserve was about 76,000 tonnes, the grade of copper was $1.53 \%$, and the grade of zinc was $0.15 \%$. On the other hand, when confidence level was set at 50\%, ore reserve was about 2,550,000 tonnes, the grade of copper was $1.33 \%$, and the grade of zinc was $0.15 \%$. These indicate that when setting confidence level higher when extracting blocks within optimal boundary in the probability model, ore reserve estimates decrease. The mean grade of the blocks within optimal boundary varied somewhat depending on the confidence level of the probability model but did not show any particular pattern.

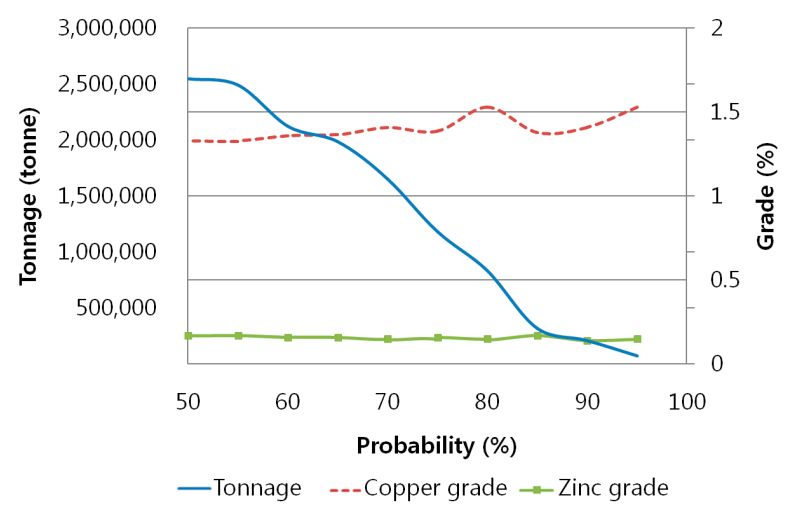

Figure 11. Probability-tonnage-grade graph for ore reserve estimation.

\section{Discussion}

Figure 12 is the plan view of the probability model formed by separating when considering variation in copper prices without considering variation in zinc prices, and when considering variation in zinc prices without considering variation in copper prices. The results of the probability model formations show that when considering variation in copper prices only, significant uncertainty exists in open pit optimization results, whereas when considering variation in zinc prices only, uncertainty is small in boundary optimization results. These results of probability model formations by separating 
the case of considering only the variation in copper prices and the case of considering only the variation in zinc prices suggest that, in the case of copper-zinc mixed deposits in the study area, variation in copper prices has greater impact on uncertainty of open pit optimization results than variation in zinc prices does.
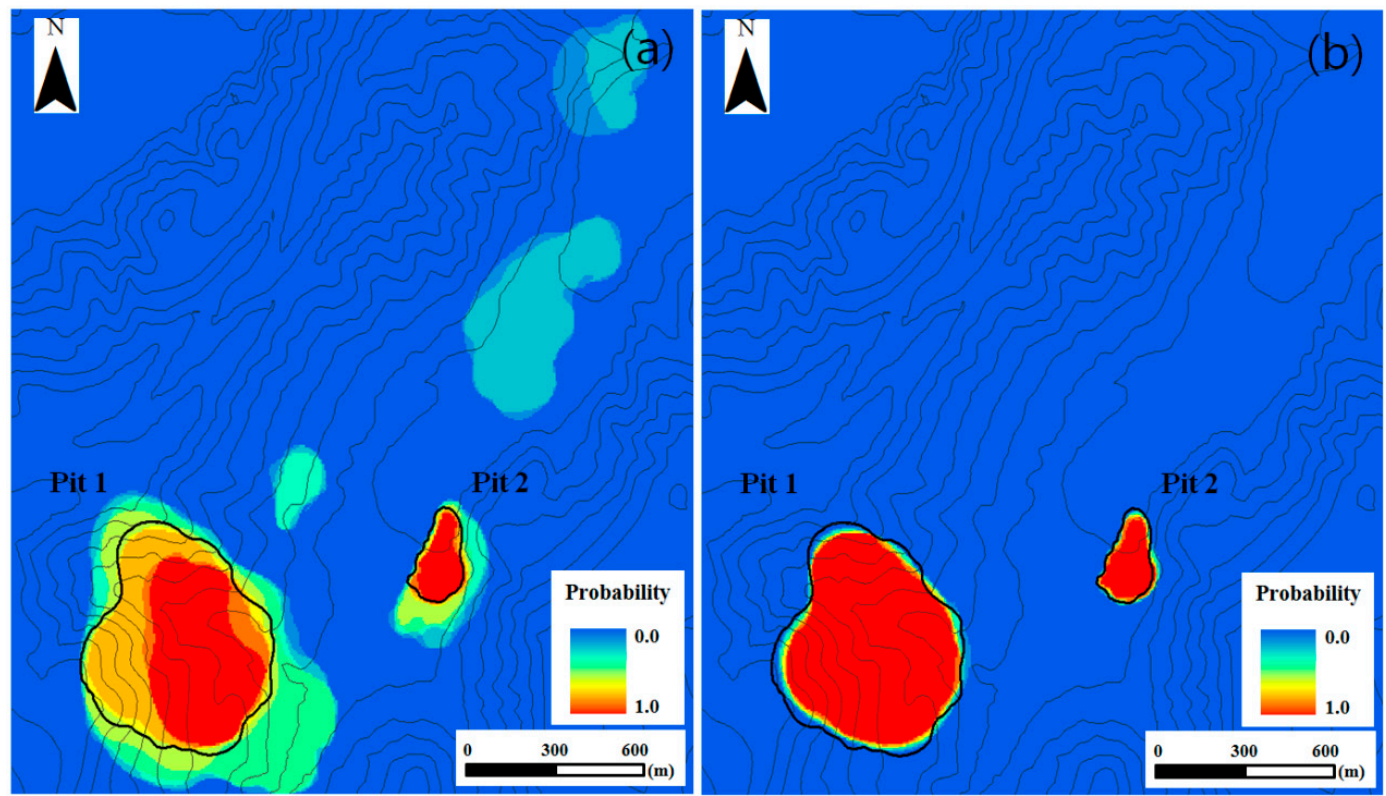

Figure 12. Probability model representing the uncertainty in the pit optimization results. (a) Case 1 when considering the variation of copper prices only; (b) Case 2 when considering the variation of zinc prices only.

\section{Conclusions}

This study presented a method to quantitatively represent the uncertainty in open pit optimization results due to variation in mineral prices using a probability model. The results of applying the proposed method to the copper-zinc mixed deposits showed that significant uncertainty exists in open pit optimization results considering the variation in copper and zinc prices for the past 10 years. In addition, the study was able to quantify the probability that each block that represents deposits is included within the open pit optimal boundary when copper and zinc prices increase or decrease from the current reference prices. Using these probabilities, reserves of the deposits were estimated as a function of confidence level. When confidence level is set at $90 \%$ or higher, reserve was estimated to be about 76,000 tonnes, and when confidence level was set at 50\% or higher, reserve was estimated to be about 2,550,000 tonnes. This suggests that the proposed method also has a potential for use in ore reserve estimation. The results of probability model formation by separating the cases of variation in copper prices only and in zinc prices only showed that the uncertainty in the results of open pit optimization in the study area was more influenced by the variation in copper prices than by that in zinc prices.

In this study, the uncertainty in open pit optimization results was represented by a probability model considering only the variations in mineral prices. However, the proposed method is expected to be applicable in a similar fashion, when variations in geological variables as well as other economic variables such as production costs, exchange rates, and taxes are considered. In future work, it would be interesting to develop an extended method to simultaneously consider the uncertainties of multiple variables because it can change the results of uncertainty representation for open pit optimization. 
The proposed method is applicable to a wide range of deposits for a general purpose, and may be used in combination with various open pit optimization algorithms. Therefore, it is expected to be a valuable tool to assist sound long-term development planning of open pit mines.

Acknowledgments: This work was supported by a Korea Institute of Energy Technology Evaluation and Planning (KETEP) grant, funded by the Korean Government's Ministry of Trade, Industry, and Energy (2013T100100021) and Basic Science Research Program through the National Research Foundation of Korea (NRF) funded by the Ministry of Education (2015R1D1A1A01061290). The authors thank anonymous reviewers for their critical comments and suggestions, which improved the quality of our manuscript.

Author Contributions: Jieun Baek and Yosoon Choi conceived and designed the experiments; Jieun Baek performed the experiments; Yosoon Choi analyzed the data; Han-su Park contributed reagents/materials/analysis tools; Jieun Baek and Yosoon Choi wrote the paper.

Conflicts of Interest: The authors declare no conflict of interest.

\section{References}

1. Lerchs, H.; Grossmann, L. Optimum design of open-pit mines. Can. Min. Metall. Bull. 1965, 58, 47-54.

2. Picard, J.C. Maximal closure of a graph and applications to combinatorial problems. J. Manag. Sci. 1976, 22, 1268-1272. [CrossRef]

3. David, M.; Dowd, P.A.; Korobov, S. Forecasting departure from planning in open pit design and grade control. In Proceedings of the 12th International APCOM Symposium, Golden, CO, USA, 8-12 April 1974.

4. Lane, K.F. The Economic Definition of Ore: Cutoff Grade in Theory and Practice, 1st ed.; Mining Journal Books Limited: London, UK, 1988; pp. 1-147.

5. Caccetta, L.; Giannini, L.M. An application of discrete mathematics in the design of an open pit mine. Discrete Appl. Math. 1988, 21, 1-19. [CrossRef]

6. Berlanga, J.M.; Cardona, R.; Ibarra, M.A. Recursive formulae for the floating cone algorithm. Int. J. Surf. Min. Reclam. Environ. 1989, 3, 141-150. [CrossRef]

7. Zhao, Y.; Kim, Y.C. A new ultimate pit limit design algorithm. In Proceedings of the International 23rd APCOM Symposium, Tucson, AZ, USA, 7-11 April 1992.

8. Dowd, P.A.; Onur, A.H. Open-pit optimization-Part 1: Optimal open pit design. Trans. Inst. Min. Metall. 1993, 102, A95-A104.

9. Yamatomi, J.; Mogi, G.; Akaike, A.; Yamaguchi, U. Selective extraction dynamic cone algorithm for three-dimensional open pit designs. In Proceedings of the 25th International APCOM Symposium, Brisbane, Australia, 9-14 July 1995.

10. Underwood, R.; Tolwinski, B. A mathematical programming viewpoint for solving the ultimate pit problem. Eur. J. Oper. Res. 1998, 107, 96-107. [CrossRef]

11. Hochbaum, D.S.; Chen, A. Performance analysis and best implementations of old and new algorithms for the open-pit mining problem. Oper. Res. 2000, 48, 894-914. [CrossRef]

12. Gershon, M.E. Mine scheduling optimization with mixed integer programming. Min. Eng. 1983, 35, 351-354.

13. Busnach, E.; Mehrez, A.; Sinuany-Stern, Z. A production problem in phosphate mining. J. Oper. Res. Soc. 1985, 36, 285-288. [CrossRef]

14. Gershon, M. Heuristic approaches for mine planning and production scheduling. Int. J. Min. Geol. Eng. 1987, 5, 1-13. [CrossRef]

15. Souza, M.J.F.; Coelho, I.M.; Ribas, S.; Santos, H.G.; Merschmann, L.H.C. A hybrid heuristic algorithm for the open-pit mining operational planning problem. Eur. J. Oper. Res. 2010, 207, 1041-1051. [CrossRef]

16. Cullenbine, C.; Wood, R.K.; Newman, A. A sliding time window heuristic for open pit mine blcok sequencing. Optim. Lett. 2011, 5, 365-377. [CrossRef]

17. Chicoisne, R.; Espinoza, D.; Goycoolea, M.; Moreno, E.; Rubio, E. A new algorithm for the open-pit mine scheduling problem. Oper. Res. 2012, 60, 517-528. [CrossRef]

18. Epstein, R.; Goic, M.; Weintraub, A.; Catalán, J.; Santibáñez, P.; Cancino, R.; Gaete, S.; Aguayo, A.; Caro, F. Optimizing long-term production plans in underground and open-pit copper mines. Oper. Res. 2012, 60, 4-17. [CrossRef]

19. Dendy, B.; Schofield, D. Open-pit design and scheduling by use of genetic algorithms. Trans. Inst. Min. Metall. 1994, 103, A21-A26. 
20. Dendy, B.; Schofield, D. The use of genetic algorithms in underground mine scheduling. In Proceedings of the 25th International APCOM Symposium, Brisbane, Australia, 9-14 July 1995.

21. Elevli, B. Open pit mine design and extraction sequencing by use of OR and AI concepts. Int. J. Surf. Min. Reclam. Environ. 1995, 9, 149-153. [CrossRef]

22. Tolwinski, B.; Underwood, R. A scheduling algorithm for open pit mines. IMA J. Manag. Math. 1996, 7, 247-270. [CrossRef]

23. Caccetta, L.; Hill, S.P. An application of branch and cut to open pit mine scheduling. J. Glob. Optim. 2003, 27, 349-365. [CrossRef]

24. Boland, N.; Dumitrescu, I.; Foyland, G.; Gleixner, M. LP-based disaggregation approaches to solving the open pit mining production scheduling problem with block processing selectivity. Comput. Oper. Res. 2009, 36, 1064-1089. [CrossRef]

25. Bienstock, D.; Zuckerberg, M. Solving LP relaxations of large-scale precedence constrained problems. In Proceedings of the 14th international conference on IPCO (Integer Programming and Cominatorial Optimisation), Lausanne, Switzerland, 9-11 June 2010.

26. Kumral, M.; Dowd, P.A. A simulated annealing approach to mine production scheduling. J. Oper. Res. Soc. 2005, 56, 922-930. [CrossRef]

27. Ramazan, S. The new fundamental tree algorithm for production scheduling of open pit mines. Eur. J. Oper. Res. 2007, 177, 1153-1166. [CrossRef]

28. Bley, A.; Boland, N.; Fricke, C.; Froyland, G. A strengthened formulation and cutting planes for the open pit mine production scheduling problem. Comput. Oper. Res. 2010, 37, 1641-1647. [CrossRef]

29. Liu, S.Q.; Kozan, E. New graph-based algorithms to efficiently solve large scale open pit mining optimisation problems. Expert Syst. Appl. 2016, 43, 59-65. [CrossRef]

30. Godoy, M. The Effective Management of Geological Risk in Long-Term Production Scheduling of Open Pit Mines. Ph.D. Thesis, University of Queensland, St Lucia, Australia, 2003.

31. Menabde, M.; Foyland, G.; Stone, P.; Yeates, G. Mining schedule optimisation for conditionally simulated orebodies. In Proceedings of the International Symposium on Orebody Modelling and Stategic Mine Planning: Uncertainty and Risk Management, Perth, WA, USA, 22-24 November 2004.

32. Costa Lima, G.A.; Suslick, S.B. Estimating the volatility of mining projects considering price and operating cost uncertainties. J. Resour. Policy 2006, 31, 86-94. [CrossRef]

33. Golamnejad, J.; Osanloo, M.; Karimi, B. A chance-constrained programming approach for open pit long-term production scheduling in stochastic environments. J. S. Afr. Inst. Min. Metall. 2006, 106, 105-114.

34. Dimitrakopoulos, R.; Abdel Sabour, S.A. Evaluating mine plans under uncertainty: Can the real options make a difference? J. Resour. Policy 2007, 32, 116-125. [CrossRef]

35. Ramazan, S.; Dimitrakopoulos, R. Stochastic optimization of long term production scheduling for open pit mines with a new integer programming formulation. In Proceedings of the Orebody Modelling and Strategic Mining Planning Symposium, Perth, Australia, 22-24 November 2004.

36. Boland, N.; Dumitrescu, I.; Froyland, G. A Multistage Stochastic Programming Approach to Open Pit Mine Production Scheduling with Uncertain Geology. Available online: http:/ /www.optimization-online.org/ DB_HTML/2008/10/2123.html (accessed on 22 February 2016).

37. Akbari, A.D.; Osanloo, M.; Shirazi, M.A. Determination of ultimate pit limits in open mines using real option approach. IUST Int. J. Eng. Sci. 2008, 19, 23-38.

38. Albor, F.; Dimitrakopoulos, R. Algorithmic approach to pushback design based on stochastic programming: Method, application and comparisons. Trans. Inst. Min. Metall. 2010, 119, 88-101.

39. Abdel Sabour, S.A.; Dimitrakopoulos, R. Incorporating geological and market uncertainties and operational flexibility into open pit mine design. J. Min. Sci. 2011, 47, 191-201. [CrossRef]

40. Evatt, G.W.; Soltan, M.O.; Johnson, P.V. Mineral reserves under price uncertainty. Resour. Policy 2012, 37, 340-345. [CrossRef]

41. Lamghari, A.; Dimitrakopoulos, R. A diversified Tabu search approach for the open-pit mine production scheduling problem with metal uncertainty. Eur. J. Oper. Res. 2012, 222, 642-652. [CrossRef]

42. Asad, M.W.A.; Dimitrakopoulos, R. Implementing a parametric maximum flow algorithm for optimal open pit mine design under uncertain supply and demand. J. Oper. Res. Soc. 2013, 64, 185-197. [CrossRef] 
43. Alonso-Ayuso, A.; Carvallo, F.; Escuderto, L.F.; Guignard, M.; Pi, J.; Puranmalka, R.; Weintraub, A. Medium range optimization of copper extraction planning under uncertainty in future copper prices. Eur. J. Oper. Res. 2014, 233, 711-726. [CrossRef]

44. Kizilkale, A.C.; Dimitrakopoulos, R. Optimizing mining rates under financial uncertainty in global mining complexes. Int. J. Prod. Econ. 2014, 158, 359-365. [CrossRef]

45. Hall, G. Multi-mine better than multiple mines. In Proceedings of the Orebody Modelling and Strategic Mining Planning Symposium, Perth, Australia, 22-24 November 2004.

46. Elahizeyni, E.; Kakaie, R.; Yousefi, A. A new algorithm for optimum open pit design: Floating cone method III. J. Min. Environ. 2011, 2, 118-125.

47. Magassouba, M. OK Block Model Versus MIK Block Model: Optimization of the Profit Cut-off at the Northern Nevada Pit, USA. Master's Thesis, University of Nevada, Reno, NV, USA, August 2006.

48. Hustralid, W.; Kuchta, M.; Martin, R. Open Pit Mine Planning and Design Volume 1-Fundamentals, 3rd ed.; CRC Press: Leiden, The Netherlands, 2013; pp. 409-501.

(C) 2016 by the authors; licensee MDPI, Basel, Switzerland. This article is an open access article distributed under the terms and conditions of the Creative Commons by Attribution (CC-BY) license (http://creativecommons.org/licenses/by/4.0/). 